\title{
Penetration of Topically Applied Betamethasone Sodium Phosphate into Human Aqueous Humour
}

\author{
D. G. WATSON,${ }^{*}$ C. N. J. McGHEE,${ }^{*} \dagger$ J. M. MIDGLEY,${ }^{*}$ G. N. DUTTON,$\ddagger$ \\ M. J. NOBLE \\ Glasgow
}

\begin{abstract}
Summary
Gas Chromatography combined with Negative Chemical Ionisation Mass Spectrometry (GCMS) was used to determine the absorption of topically applied betamethasone sodium phosphate into the aqueous humour of human subjects undergoing routine intraocular surgery. The Betamethasone concentration was greatest in the interval 91-120 minutes following topical administration (mean peak concentration $=7.7 \mathrm{ng} / \mathrm{ml}$ ). At twelve hours post instillation the mean concentration of Betamethasone was $2.5 \mathrm{ng} / \mathrm{ml}$ and detectable levels were recorded in the aqueous humour 24 hours after application (mean concentration $0.4 \mathrm{ng} / \mathrm{ml}$ ).
\end{abstract}

The authors have previously reported data on the penetration of dexamethasone alcohol $0.1 \%,{ }^{1}$ prednisolone sodium phosphate $0.5 \%^{2}$ and prednisolone acetate $1.0 \%{ }^{3}$ into human aqueous humour utilising the highly sensitive and specific technique of Gas Chromatography with Negative Chemical Ionisation Mass Spectrometry (GCMS). ${ }^{+}$Limited data is available on the direct measurement of Betamethasone in aqueous humour of animal models ${ }^{5}$ following topical application. We used GCMS to analyse the penetration of betamethasone sodium phosphate into the aqueous humour at varying times following the topical application of eyedrops to human volunteer subjects undergoing routine cataract extraction. This work forms part of a larger ongoing study which aims to establish the aqueous humour pharmacokinetics of the commonly used, commercially available, topical corticosteroid preparations.

\section{Subjects and methods}

Patients who were scheduled to undergo routine cataract surgery were recruited to the study and informed consent was obtained in all cases. Patients with corneal disease or inflammatory ocular conditions which might affect steroid penetration into the eye were excluded from the study. None of the patients had been prescribed topical or systemic steroids in the six months prior to surgery. Sixtysix eyes of 66 patients were included. The mean age of patients included was 72 years (range 56-92 years).

Fifty microlitres of betamethasone sodium phosphate $(0.1 \%)$ solution (Betnesol: Glaxo Ltd, UK) were introduced by micropipette

\footnotetext{
* Department of Pharmacy, Division of Pharmaceutical Chemistry, University of Strathclyde, Royal College Buildings, 204 George Street, Glasgow G1 1XW. † Department of Ophthalmology, Southern General Hospital, Govan Road, Glasgow. †Tennent Institute of Ophthalmology, University of Glasgow, Western Infirmary, Glasgow G11 6NT.
}

Correspondence to: Dr C. N. J. McGhee, Senior Registrar, Tennent Institute of Ophthalmology, Western Infirmary, Glasgow G11 6NT. 
Table I Mean concentration ( $\mathrm{ng} / \mathrm{ml})$ ( \pm standard error of mean) of betamethasone in human aqueous humour at various times (min) following the topical administration of betamethasone sodium phosphate $0.1 \%$.

\begin{tabular}{|c|c|c|c|c|}
\hline \multirow{2}{*}{$\begin{array}{c}\text { Time } \\
\text { interval } \\
\text { (mins) }\end{array}$} & \multirow{2}{*}{$\begin{array}{c}\text { No. of } \\
\text { eyes } \\
(n=66)\end{array}$} & \multicolumn{3}{|c|}{$\begin{array}{l}\text { Mean conc'n in } \\
\text { aqueous humour }\end{array}$} \\
\hline & & (ng/ml) & \pm & $(\mathrm{SEM})$ \\
\hline $0-30$ & 5 & 0.0 & \pm & 0.0 \\
\hline $31-60$ & 13 & 3.8 & \pm & 1.0 \\
\hline $61-90$ & 9 & 4.2 & \pm & 0.6 \\
\hline $91-120$ & 10 & 7.7 & \pm & 1.8 \\
\hline $121-180$ & 11 & 6.5 & \pm & 1.5 \\
\hline $181-240$ & 2 & 6.9 & \pm & 1.1 \\
\hline $241-460$ & 2 & 5.3 & \pm & 2.1 \\
\hline $461-760$ & 5 & 2.5 & \pm & 0.6 \\
\hline $761-1060$ & 4 & 0.7 & \pm & 0.5 \\
\hline $1061-1430$ & 5 & 0.4 & \pm & 0.2 \\
\hline
\end{tabular}

into the lower conjunctival fornix of the eye being prepared for surgery at varied times up to 24 hours pre-operatively. Two drops each of Phenylephrine $10 \%$ and Cyclopentolate $1 \%$ were administered one hour prior to surgery to obtain mydriasis.

Twenty-nine of the operations were performed under general anaesthesia and 37 were performed under retrobulbar anaesthesia. 0.05 to 0.15 millilitres of aqueous humour were aspirated with a tuberculin syringe through a 25 gauge needle after a partial thickness corneoscleral incision had been made but before the anterior chamber had been entered. The interval between the instillation of betamethasone sodium phosphate and the aspiration of aqueous humour was noted. The aqueous samples were immediately frozen and stored at $-20^{\circ} \mathrm{C}$ until analysed by GCMS.

Two nanograms of deuterated betamethasone (containing largely the trideuterated derivative) were added to the sample of aqueous humour (which had previously been diluted to $1 \mathrm{ml}$ with high purity water). The aqueous layer was extracted with ethyl acetate $(2 \times 1 \mathrm{ml})$ and the extract chemically treated to give the di-methoxime tris-trimethylsilyl ether derivative. ${ }^{4}$ The derivatised extract was then subjected to GCMS in the negative chemical ionisation mode; the undeuterated corticosteroid present in the aqueous humour was identified and quantified with reference to the known amount of di/ trideuterated compound added before extraction. Thus the deuterated isotopomer of betamethasone co-chromatographed with the corresponding undeuterated substance and yielded ions in its mass spectrum equivalent to those obtained from the undeuterated compound together with a mass increment of 2-3 atomic mass units. This technique is suitable for the quantification of betamethasone in the $0.1-10 \mathrm{ng}$ range.

In order to detect if betamethasone sodium phospate was present in the aqueous humour ten samples were incubated with acid phosphatase following the initial extraction with ethyl acetate (acid phosphatase was found to be effective in releasing betamethasone from its phosphate in standard solutions). The enzymatically treated solution was then processed as described above for the untreated aqueous humour. No additional betamethasone could be detected after treatment with acid phosphatase.

\section{Results}

The concentrations of betamethasone in human aqueous humour at varied time intervals following the topical administration of Betamethasone Sodium Phosphate are shown in Table I. The concentrations of betamethasone in aqueous humour vs time from instillation is shown in Figure 1. Peak mean concentrations were recorded between 91120 minutes after application. Levels which are approximately $30 \%$ of the peak drug concentration were measured between eight and 12 hours and trace levels were recorded at 24 hours.

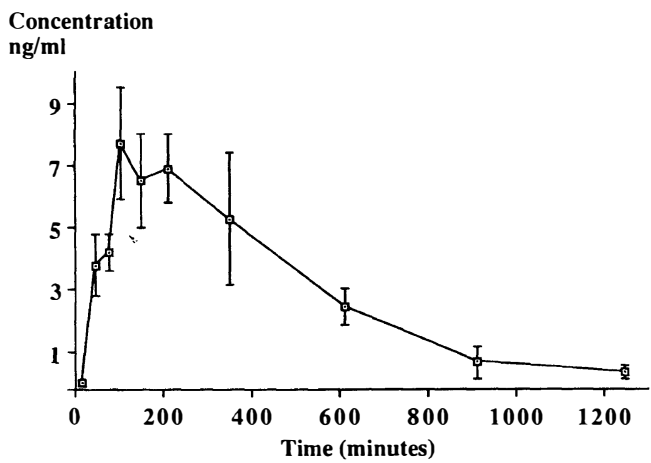

Fig. 1. Mean peak concentrations of betamethasone ( $\mathrm{ng} / \mathrm{ml} \pm S E M)$ in human aqueous humour vs time (mins) following topical application of betamethasone sodium phosphate $0.1 \%$. 
There were no statistical differences in aqueous betamethasone concentrations when the results from patients receiving general anaesthetic were compared to those who had undergone retrobulbar anaesthesia.

\section{Discussion}

In human aqueous humour the mean peak concentration of betamethasone $(7.7 \mathrm{ng} / \mathrm{ml})$ is much lower than we have previously recorded for dexamethasone alcohol $0.1 \%$ $(31.0 \mathrm{ng} / \mathrm{ml}),{ }^{1}$ prednisolone sodium phosphate $0.5 \%(25.6 \mathrm{ng} / \mathrm{ml})^{2}$ or prednisolone acetate $1.0 \%(669.6 \mathrm{ng} / \mathrm{ml})^{3}$. However, the mean concentration of betamethasone does not fall below $68 \%$ of the peak concentration within eight hours of application, whereas, the peak levels of the other three drugs fall to less than $33 \%$ of peak concentration at eight hours. The lower mean peak concentration of betamethasone when compared to dexamethasone and prednisolone acetate might be partly explained by its preparation as a phosphate; such corticosteroid preparations have been shown to be polar and thus the intact corneal epithelium presents more of a barrier to their penetration than the more lipid soluble acetate and alcohol corticosteroid derivatives. ${ }^{6,78}$ In such comparisons it is important to remember that on a weight for weight basis dexamethasone and betamethasone have a five to seven fold greater systemic anti-inflammatory activity than prednisolone. ${ }^{9}$ However, it has been suggested on the basis of evidence from animal models that these differences in systemic anti-inflammatory activity may not be directly extrapolated to the ocular milieu. ${ }^{10}$

To the authors' knowledge there are no previously published data on betamethasone concentrations in human aqueous humour following topical administration. However, betamethasone has been studied in rabbit eyes following topical administration using radioimmunoassay techniques. ${ }^{5}$ Using this method peak aqueous humour concentrations of $72.2 \mathrm{ng} / \mathrm{ml}$ were recorded. It was also noted that greater aqueous humour concentrations were obtained with $0.5 \%$ and $1.0 \%$ preparations of betamethasone but at these higher concentrations significant levels of betamethasone were detected in the contralateral control eye perhaps suggesting an overly sen- sitive technique. The remit of our study was to analyse the intraocular penetration of commercially available topical corticosteroids, therefore, our data is limited to the $0.1 \%$ concentration of betamethasone sodium phosphate. None the less it is worth noting that previous animal studies have shown that betamethasone sodium phosphate, prednisolone sodium phosphate, and prednisolone acetate all achieve significantly higher aqueous levels when delivered in $1.0 \%$ preparations when compared to lower concentrations. ${ }^{5,11,12}$

Among the possible variables we found no significant differences in aqueous levels of betamethasone when patients were grouped by age, sex, or type of anaesthetic. It might be postulated that eyes with cataract do not behave identically to inflamed eyes, in which intraocular inflammation can interfere with the epithelial barrier to a water soluble corticosteroid ${ }^{13}$ or that the application of cyclopentolate and phenylephrine might influence the surface characteristics of the eye and therefore the penetration of topical steroids. Unfortunately, these are variables which are unavoidable in human research; the former we cannot influence the latter we hope has been minimised by the standardisation of preoperative mydriatic doses.

Although betamethasone sodium phosphate $0.1 \%$ does not reach the mean peak aqueous concentrations of dexamethasone alcohol $0.1 \%$, prednisolone sodium phosphate $0.5 \%$ or prednisolone acetate $1.0 \%$ it does have a longer aqueous half life. Therefore topical application two to three times daily may be sufficient to maintain peak betamethasone concentrations in the aqueous humour. However, we have yet to analyse the additive effects of repeat application and as such the aqueous kinetics of the corticosteroids examined so far cannot be fully predicted. Hopefully when this data is available more rational regimens may be applied for the topical administration of betamethasone and the other topical ophthalmic corticosteroid preparations.

The work described has been supported by a grant from the Scottish Hospital Endowments Research Trust (Grant No. HERT 761). The authors are grateful to Dr J. Williamson, Dr W. M. Doig, Dr P. M. Kyle and Dr J. Dudgeon for providing aqueous samples. 


\section{Proprietary statement}

None of the authors has any commercial or proprietary interests in Betamethasone eyedrops or any other ophthalmic corticosteroid eyedrops.

\section{References}

${ }^{1}$ Watson DG, Noble MJ, Dutton GN et al: Penetration of topically applied dexamethasone alcohol into human aqueous humour. Arch Ophthalmol 1988, 106: 686-7.

${ }^{2}$ McGhee CN, Watson DG, Noble MJ et al: Penetration of topically applied prednisolone sodium phosphate into human aqueous humour Eye 1989, 3: 463-7.

${ }^{3}$ McGhee CN, Watson DG, Midgley JM et al: Penetration of Synthetic Corticosteroids into Human Aqueous Humour. Eye 1990 (In press).

${ }^{4}$ Midgley JM, Watson DG, Healey TM, Noble M: The quantification of synthetic corticosteroids using isotope dilution gas chromatography negative chemical ionisation mass spectrometry. Biomed Environmental Mass Spect 1988, 15: 479-83.

${ }^{5}$ Baba S, Mishima H, Miyachi Y: Levels of CyclicAMP, Cyclic-GMP and betamethasone in the aqueous humour following topical administration of betamethasone in rabbit eyes. Hiroshima $J$ Med Sci 1983, 3: 301-4.

${ }^{6}$ Flint FR and Morton DJ: Effect of derivatisation of the bioavailability of ophthalmic steroids: Development of an in vitro method of evaluation. Arch Ophthalmol 1984, 102: 1808-9.

${ }^{7}$ Kupferman A, Pratt MV, Suckewer K et al: Topically applied steroids in corneal disease: 111 . The role of drug derivative in stromal absorption of dexamethasone. Arch Ophthalmol 1974, 91: 373-6.

${ }^{8}$ Hull DS, Hine JE, Edelhauser HF, Hyndiuk RA: Permeability of the isolated rabbit cornea to corticosteriods. Invest Ophthalmol 1974, 13: 457-9.

${ }^{9}$ Havener WH: Corticosteroid therapy in Ocular Pharmacology (fifth edition) ed. William $\mathrm{H}$. Havener; CV Mosby Co, St Louis. 1983; 433-500.

${ }^{10}$ Leibowitz HM: Management of inflammation in the cornea and conjunctiva. Ophthalmology 1980;87: 753-8.

${ }^{11}$ Kupferman A and Leibowitz HM: Topically applied steroids in corneal disease: V1. Kinetics of prednisolone sodium phosphate. Arch Opthalmol 1974, 92: 331-4.

${ }^{12}$ Leibowitz HM and Kupferman A: Kinetics of Topically administered prednisolone acetate. Arch Ophthalmol 1976, 94: 1387-9.

${ }^{13}$ Cox WV, Kupferman A, Leibowitz HM: Topically applied steroids in corneal disease: 1 . The role of inflammation in stromal absorption of dexamethasone. Arch Opthalmol 1972, 88: 308-11. 